\title{
دور القنون في تعزيز التربية الأخلاقية لتحسين جودة التعلم عن بعد
}

\section{The role of arts in promoting moral education to improve the quality of distance learning}

\author{
د. سهام على البدري عبد العظيم \\ دكتوراه الفلسفة في الفنون التطبيقية \\ أستاذ مساعد -كلية التربية - جامعة نجران - المملكة العربية السعودية
}

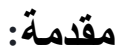

إن الجودة في التعليم هي القوة الدافعة المطلوبة لدفع النظام التعليمي بشكل فعال ليحقق أهدافه ورسالته. وقد فرض نمط التعلم عن بعد، شأنه شأن النمط التقليدي، مجموعة من القيم والأخلاقيات التي لا بد من التزامها سعياً نحو تحقيق الغايات الإنسانية المنشودة من ورائهما بكل أبعادها، ويشير معنى أخلاقيات التعلم والعمل عن بعد إلى مجموعة من المعايير الأخلاقية التي يجب الالتزام بها في المؤسسة التعليمية والمنتسبين إليها معلماً وطالباً وكل صاحب، ويعد انتهاك هذه المعايير تصرفاً لا أخلاقياً. تلك الأخلاقيات للتعلم تعني تلك القيم التي تعتمد على مثل الفرد العليا من أجل الانضباط والتعلم والعمل الجادين، ما يعني أن على الفرد التدرب على اتباع هذه القيم لتحقيق تلك الغاية، والأمر سيان في كلا النمطين التقليدي أو عن بعد، ويتحقق تدريب الفرد لذاته على تللك الأخلاقيات من خلال بناء العادات وتتفيذها ثم المثابرة بالالنزام والتركيز عليها.

ولقد درس الكثير من الفلاسفة موضوع الفن وعلاقته بالأخلاق وابعاده التربوية والاخلاقية لبناء الأنسان وورد الفن في معجم الفلسفة على انه يطلق على ما يساوي الصنعة. أو انه نعبير خارجي عما يحدث في النفس من بواعث وتأثرات بواسطة الخطوط أو الألوان أو الحركات أو الأصوات أو الألفاظ. وتعني كلمة الفن مجمل الوسائل، والمبادئ التي يقوم الإنسان بواسطتها بإنجاز عمل يعبر عن مشاعره وأفكاره. ونرى الفن يوجه الناس أخلاقيا ويعمل علي تحسين اوضاعهم وكونه الفن بسيطا يخاطب عامة الناس . مشكلة البحث: - 20

تكمن مشكلة البحث في جوانب متعددة في مجتمعاتتا وحياتتا المعاصرة من معطيات ثقافيه واجتماعية وتربوبة تؤثر في القيم والاتجاهات السلوكية.

وفي السياقات المختلفة لهذه الأخلاقيات والخاصة بنمط التعلم والعمل عن بعد والتي تفرضها طبيعته الافتراضية نجد أنها ترسم ثلاثة مسارات وهي الحرية والمسؤولية والالتزام، وهذه المسارات الثلاثة مترابطة مع بعضها البعض بشكل منين إن افترضنا أنها قد تصبح فاعلة من دون الأخرى فهذا مما قد نخطئ 
فيه، فالحرية قد تكون مصحوبة بالفوضوية وبالكنب والغش والتسيب والتعدي على حريات الآخرين وغير

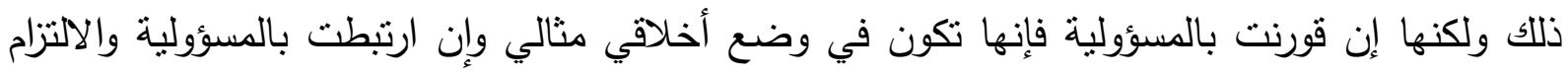
فإنها تصبح أكثر فعالية ومثالية وهذا أهم منطلب قد يفرضه فئه ندط التعلم أو العمل عن بعد، ولنسوق مثالاً

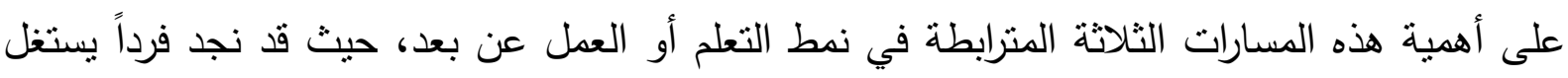

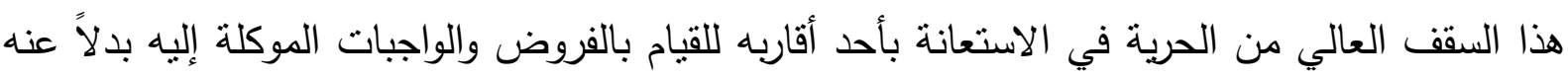

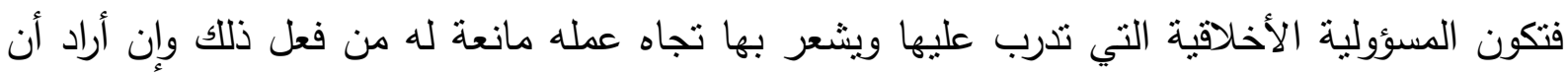
يتغيب عن وقت إنجاز العمل أو إنجاز فروضه يكون الالنزام الأخلاقي الذي تدرب عليه كأخلاقيات تعلم

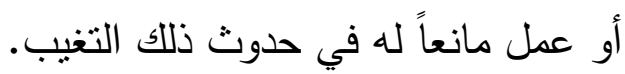
فترى الباحثة انه لابد من نتمية الالتزام الأخلاقي للطلاب بلبعض فئ الوسائل التي منها الفن وما يحمله من

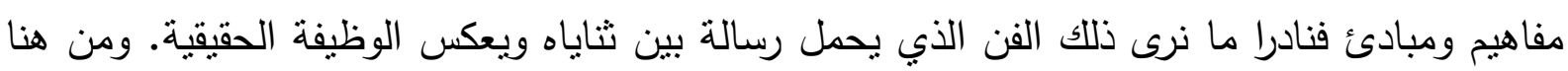

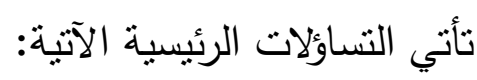

1. هل يؤثر الفن على تتمية التربية الأخلاقية؟ r. هل تعزيز التربية الأخلاقية لدى الطلاب يؤثر في جودة التعلم عن بعد؟ التهبه

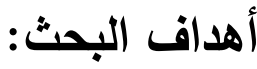

تسعى الباحثة من وراء هذا البحث إلى تحقيق الأهداف التالية:

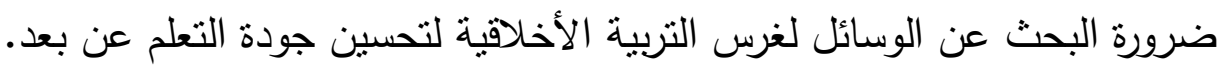
مناقثة التأثثر التربوي والأخلاقي للعمل الفني كمادة معبرة يتجاوز تأثيرها الوظيفة التقليدية.

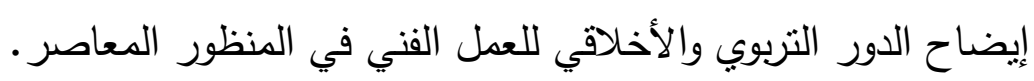

يمكن تلخيص أهمية البحث في النقاط التالية: • تأكيد تأثير العمل الفني وخصوصاً في عصر العولمة على المستوي الأخلاقي لمجتمعاتتا . • أن البحث في الفن والعمل الفني حاجة ملحة لتفسيره بمعانيه الفلسفية والفنية وربطها بالمعطيات الثقافية السائدة في المجتمع •ومن هذه المنطلقات يأتي هذا البحث كمحاولة للإسهام في تحقيق بأهمية الفن والعمل الفني وتفعيل دوره في توفير الحرية والمسؤولية والالتزام، وتحققها في شخص المتعلم مما يحقق المثالية الأخلاقية بشكلها المطلوب في نمط التعلم أو العمل عن بعد. 


\section{منهجية البحث:}

نظراً لطبيعة البحث باعتباره يهدف إلى البحث في الأثر الاخلاقي والتربوي الذي يقدمه الفن فقد اعتمدت

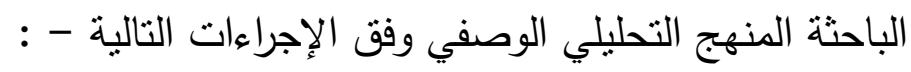
• التربية الأخلاقية أمر هام في التعلم عن بعد لتحسين جودنه.

دراسة وتحليل بعض من الأدبيات التي تبحث في مفاهيم الفن وأثره الاخلاقي والتزبوي .

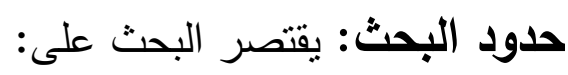

ا. دراسة تأثثر الفن على التربية الأخلاقية التي بدورها ترتبط بتحسين جودة التعلم عن بعد. r. معرفة أنواع الفنون ووسائل تدريسها.

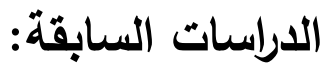

دراسة صبا قيس الياسري 11 لـ، الفن ودوره الاجتماعي والتريوي وإمكانية التفعيل في المجتمعات

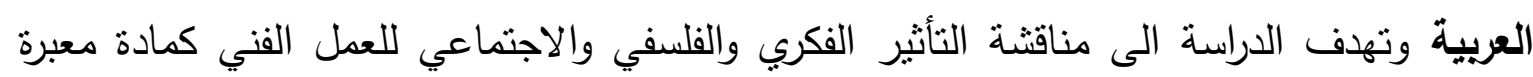
يتجاوز تأثثرها الوظيفة التقليدية كذلك إيضاح الدور الاجتماعي والتربوي للعمل الفني في المنظور

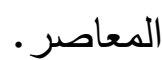

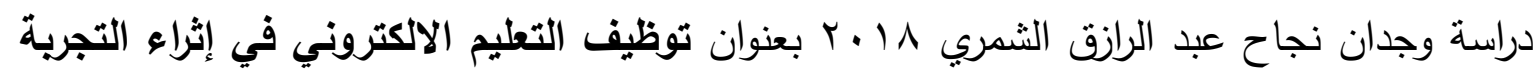

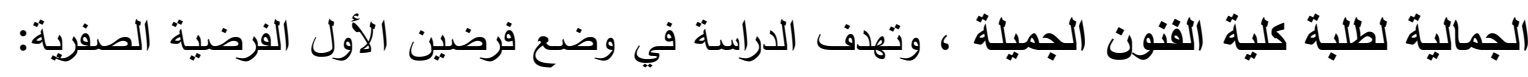

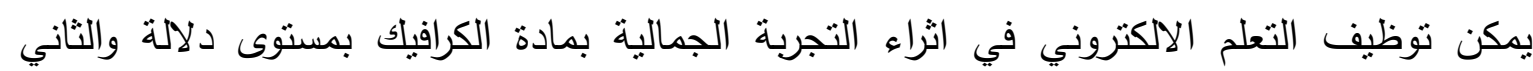

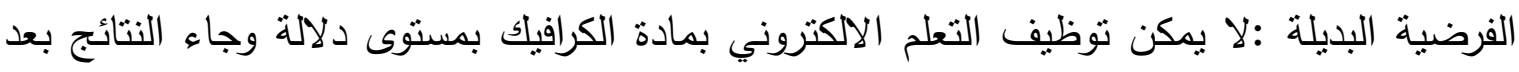
تطبيق التجربة بإثبات الفرض الأول (الفرضية الصفرية).

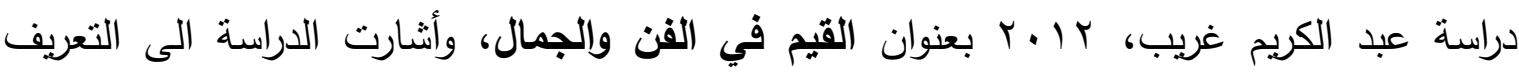
والوصف والتحليل لعدة مكونات لمنظومة التربية على قيم الفن والجمال، هذا إلى جانب الرؤية

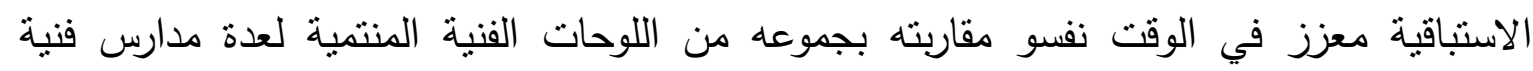

$$
\text { وتشكيلية. }
$$

التربية الأخلاقية والتعلم عن بعد: التربية الأخلاقية هي : محئ الاجلاصه و

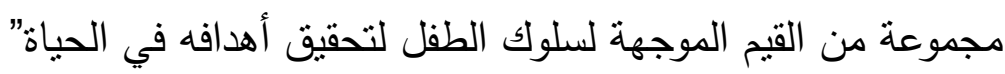

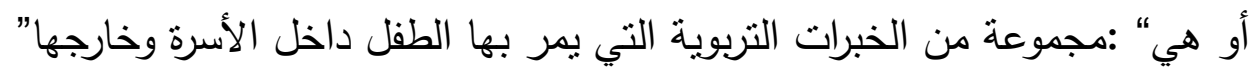


ويشار أن التربية الأخلاقية هي: “مجموعة من المبادئ الخلقية والفضائل السلوكية والوجدانية التي يجب

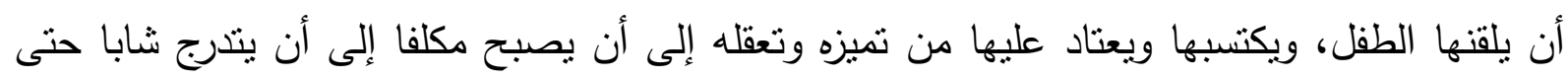

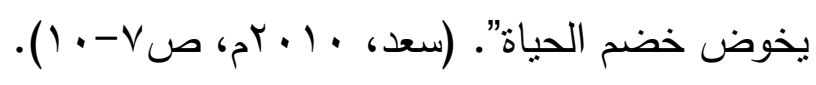

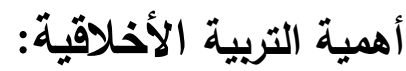

تعتبر الأخلاق قوة دافعة للسلوك والعمل، فالقيم المرغوب فيها متى تأصلت في نفس الفرد أو المتعلم فإنه

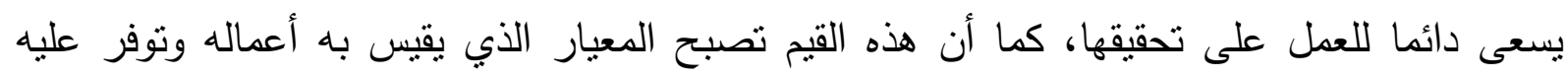

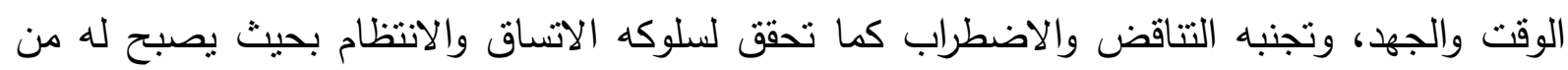

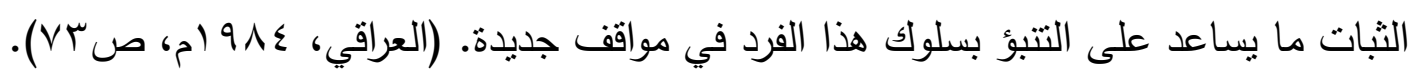

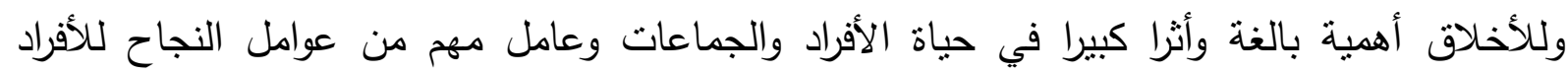

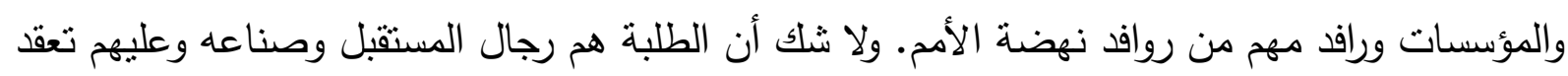

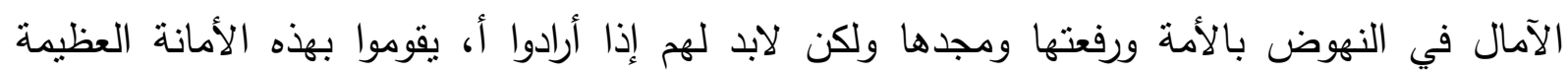
والمسؤولية الكبيرة أن يتحلوا بالأخلاق الحسنة الحميدة.

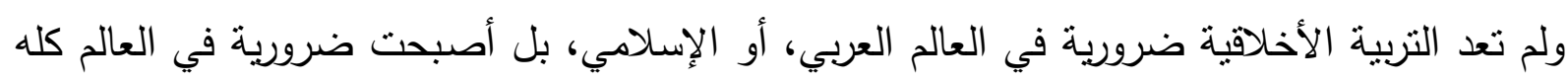
يسعى اليها الثرق والغرب، الأغنباء والفقراء. وصار تدفق المعلومات عن تلاك الثورة الأخلاقية والانحرافات التي تعاني منها البشرية الآن في كل

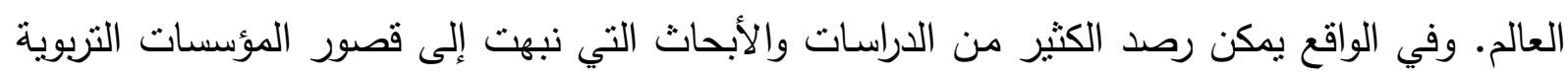

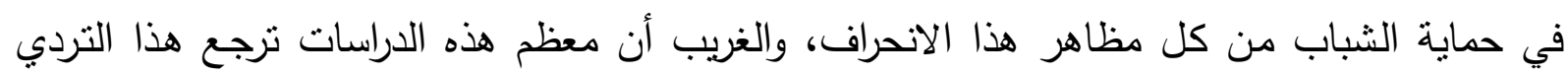

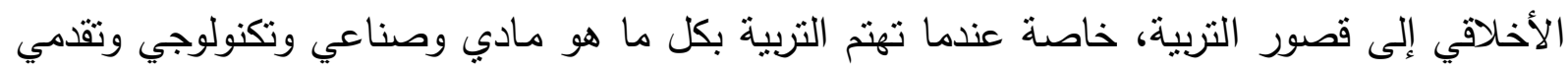

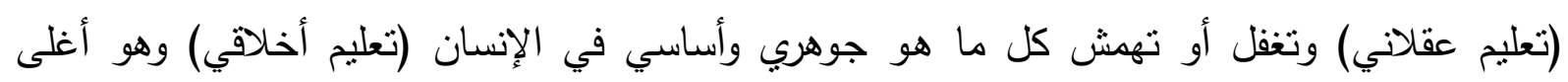

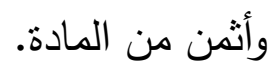
وكثير من الدراسات أكدت أن مثل هذه التربية لا يمكن إلا أن تتنج مثل هذه الأجيال، أجيال تربت على الألى

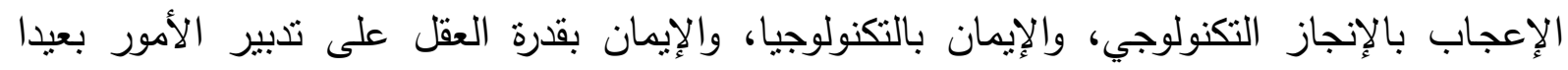

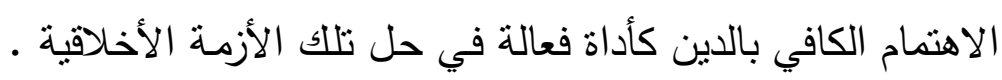
ومع التغير الحادث في عالم اليوم طغت سلوكيات عديدة غير أخلاقية منها سلوكيات منحرفة متل: الكذب -الغش والاحتيال -النصب -النهب -عدم الالتزام بالوعود -التهرب من المسئوليات • انهيار الاعصاب عند اقل الخلافات فتنفلت الاعصاب لتسمع جميع نغمات القذائف و الثنائم و كثير جدا من لنال المظاهر التي يعف اللسان عن ذكرها. 
وهناك مشاكل في الأسرة والمدرسة والجامعة والأعلام والثارع ومؤسسات العمل ومواقع الإنتاج وهناك

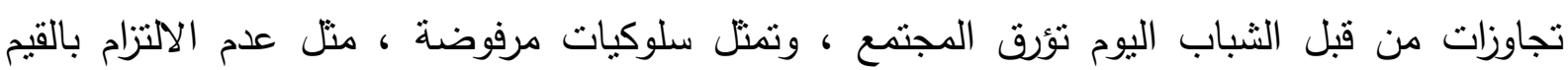

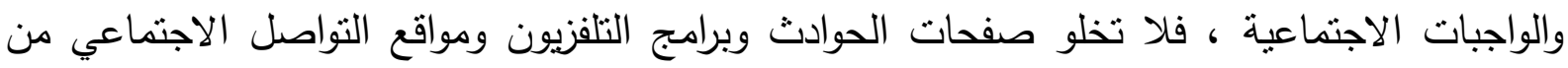
رصد سلوكيات غريبة على مجتمعنا متل العدوان على الأرحام والانحلال الخلقي وحمل السلاح والتعاطي

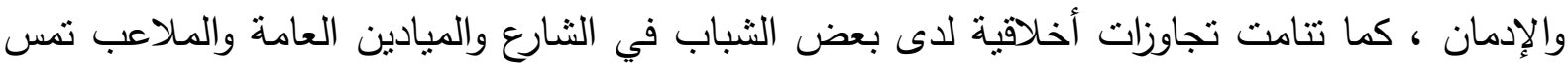

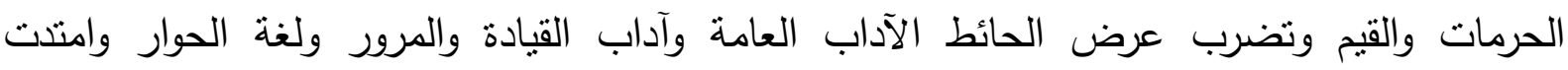

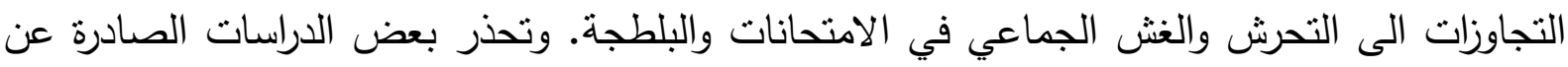

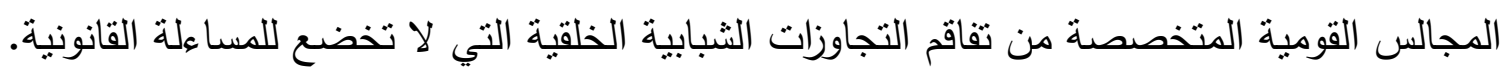
للإلك فإن وجود السلوك الأخلاقي في التعلم الرقمي أمر هام ومن منطلبات نظام التعلم عن بعد، فالتقافة

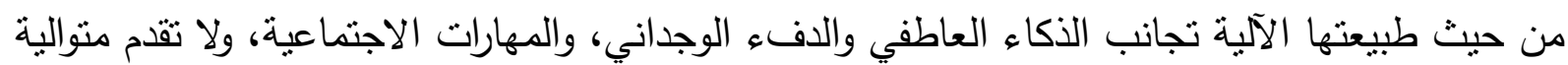
معرفية من القيم، ولا تُعنى بتصويب السلوك الخاطئ.

وإذا كان المعلم مسؤولا عن تلبية حاجات المتعلم: العاطفية، والاجتماعية، والأخلاقية في نظام التعليم المباشر، فقد اختلف الأمر كثيرا في فلسفة التعليم عن بعد، وفي الأجهزة التي تبرمج محتوى المنهج التعليمي رقميَّا.

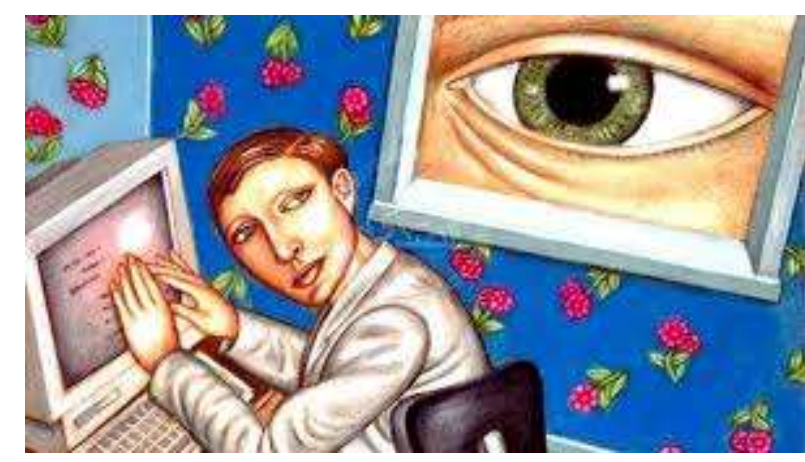

شكل ( ) تعبر عن مراقبة السلوك الأخلاقي في التعلم الرقمي

حيث نجد أن مخرجات الجودة من التعلم عن بعد :وتتمل ثلاثة أبعاد أساسية وهي : البعد الأول :المهارات المعرفية التي سيكتسبها الطالب، التي تحسن من مهاراته ومعارفه، وتعده أكاديمياً للمواطنة والعمل. البعد الثاني :إكساب المتعلم مهارات التعلم الضرورية المطلوبة، التي تعمل على نجاح البرنامج من خلال: مصادر المعلومات، والتفكير المنطقي، ومهارات الفهم القرائي، ومهارات التقييم، وإكساب المتعلم

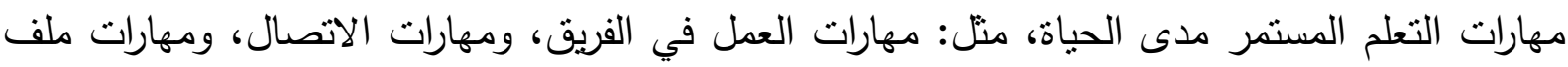


الإنجاز، ومهارات إدارة الوقت، وإكساب المتعلم مهارات الاستخدام الأمثل لتكنولوجيا المعلومات والاتصالات، منل: مهارات استرجاع المعلومات، ومهارات استخدام البريد الالكتروني وحجرات التحدث (الثات)، ومهارة الوصول للمعلومات.

البعد الثالث :اعتماد البرنامج لاى المؤسسات التربوية، بحيث نكون خبرات المتعلم كافية لترشيحه للوظائف المميزة بين المقاطعات. ولكن الأمر هو أبعد من ذللك بكثير؛ فنظريات السلوك الإنساني تثوكد أن الموضوع ليس مجرد أداة تحويل وإعادة إنتاج المادة العلمية، بل إعادة تشكيل السلوك الإنساني في أساس تكوينه بالدرجة الأولى من حيث المشاعر والانفعالات، والقيم والأخلاق؛ ولذا ظهر مفهوم “أنسنة” التكنولوجيا وشراكتها الإنسانية، فالمحتوى الإككترني الجيد لابد أن يراعي شخصيات المتعلمين، ويحقق أهدافهم العاطفية؛ وإلا تحول التعليم الرقمي إلى محتوى معرفي خال من المشاعر الإنسانية والتقهم العاطفي، وغابت تتمية المهارات

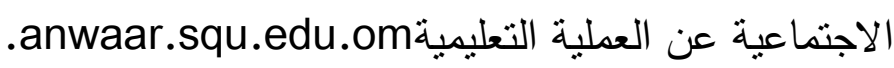
هنا، يظهر أن التربية الأخلاقية في التعلم الرقمي ضرورة لا غنى عنها، لأن الأخلاق ما زالت مفتقرة إلى معيار تمييزي لها؛ فإنها تجعل المسؤولية الأخلاقية والتجربة الحسية واجبة في التعلم عن بعد بما بمكن من تحقيق التربية السليمة المتكاملة لجوانب شخصية المتعلم الرقمي. وعليه؛ فإنه من الأهمية إعادة قراءة العناصر الجوهرية في حقل الأنثروبولوجيا من قبيل الاهتمام بامتلاك الإنسان لبعدين، وتأصيل حقيقته الوجودية المتمنلة في الاهتمام بالبعد الروحي والاهنمام بالكمال والسعادة الروحية والميتافيزيقية للإنسان، وأن يستقيد بنحو من الأنحاء من الوسائل التقنية، وأن يتحرر من قيودها في الوقت نفسه من خلال الاستفادة الصحيحة منها. وبذلك فإن ارتباطنا مع التكنولوجيا سيكون بسيطا ومريحا بشكل مذهل. وبهذه الرؤية لا إثكال في دخول التكنولوجيا إلى حياة الإنسان وأموره اليومية لوجود إمكانية دائمة وسهلة

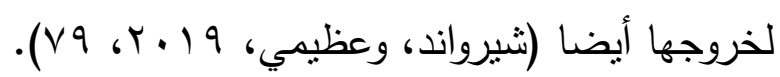
ومجمل القول أنه لكي تكون دول العالم اليوم قادرة على المنافسة العالمية في التعليم، ومسايرة التحولات الكبرى في الاقتصاد، وتحقيق أعلى مراتب التقدم العلمي والتكنولوجي؛ فإنه ينبغي عليها إلى جانب نزويد المتعلم بالمعارف والمهارات أن تزوده كذلك بالقيم ومعايير الحُكم الأخلاقي. الأثز التربوي والأخلاقي للفتون: وبقصد بالفنون تلك التي نميزها بأنها فنون تشكيلية أو مرئية وإذا توخينا الدقة في التعبير فلابد أن ندخل في نطاقها فنون الأدب والموسيقى وهناك خصائص معينة مشتركة بين كل الفنون. 
وقد درس الكثير من الفلاسفة موضوعة الفن وعلاقته بالأخلاق. وابعاده التربوية لبناء الإنسان في حين نبذ الكثير من الناس لاسيما بعض رجال الدين الفن ونظروا اليه نظرة الثك والربية، باعتباره شيئا فائضا زائدا ومضيعة للوقت فلا جدوى منه ولا نفع. ووصلت النظرة الأخلاقية الى ذروتها عند بعض النقاد والفلاسفة الذين بضعون الأخلاق فوق الجمال ويرون أن الفن في أساسه عمل أخلاقي سواء فيما يطرحه أو عند الخلق والابداع. ويرى جورج سانتيانا أنه توجد علاقة بين الأحكام الجمالية والأحكام الأخلاقية غير أن التمييز بينهما يعد أمرا هاما. وإذا كانت الاخلاق تهتم بالعلاقة بين العمل وأثياء أخرى بينما يدربنا الموقف الجمالي على الانتباه الى العمل الفني لذاته فحسب ويهتم بالخصائص الداخلية للعمل وبناءا على ذلك فان الأخلاق

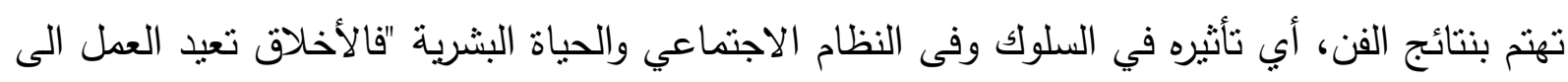

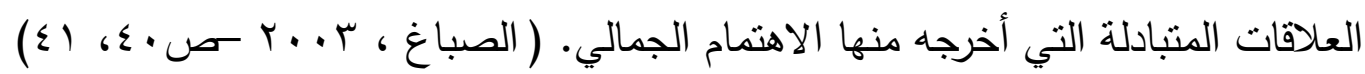
ولكن مع كل تلك الآراء، فلم نجد مجنمع يخلو تماما من الظواهر الفنية. وأن تاريخ الفن انما هو تاريخ الإنسانية. ثم ان علاقة الفن بالتربية الإنسانية قد اتى ملازما للإنسان وهو طفلا. عندما وصفه البعض بأنه لا يتعدى ان يكون (لعبا) وهم بذلك يصفون اهم ميزة انسانية وأهم وظيفة سيكولوجية واجتماعية والتي يتعلم بها الانسان اولى أسباب حياته. ووصف الفن باللعب لا يقلل من أهميته بل بعظم منها. وصحيح ان الفنان ليس واعظا. ولا خطيبا في جامع ولا كنيسة. ولكنه عندما يقدم لوحة فنية تتضمن دعوة للالتزام بقيم الحق والخير • أو يعرض مسرحية يدعوا فيها الناس الى التسامح والحب. فأنه قد يؤثر بالناس فيما يخص تعزيز الأخلاق. فكان الفن العربي الاسلامي وما زال نشاطا أخلاقيا اعتمادا على ايمان الفنان المسلم بخدمة الفن للإنسان. وطالما ان الاخلاق غايتها صناعة السعادة للإنسان فأن الفنون هي الأخرى التي تصنع السعادة. وهكذا فأن الفنون لا تتعارض مع الأخلاق طالما كانت تخدم الانسان من أجل وجوده وسعادته. ونحن ان أردنا الغوص في تاريخ البشرية نجد ان الفنون ولات مع ولادة الاديان وولدت معها بين جدران المعابد. وارتبطت بالأخلاق منذ أقدم العصور • فكم من شعائر دينية تجسدت فيها اروع الممارسات الفنية. وكم من طقوس الهبت المشاعر وقربت الأيمان باله. الم يكن صوت قارئ القرآن يخشع القلوب؟ وكم من اناس عرفوا الدين من خلال الافلام السينمائية أكثر مما عرفوه من محاضرات في المساجد والجوامع؟ والفن الملتزم بالأخلاق يلعب دورا أكبر واهم من بعض اصحاب الخطب والمواعظ. لا سيما اذا كان فنا نقيا صافيا خاليا من المطامع والغايات المادية. وأن الفنان الحقيقي الصادق يستمد ما بدور حوله من وقائع ومن احداث التاريخ ويجسدها على شكل عمل فني يساعد على اعادة صناعة الانسان وقيمه

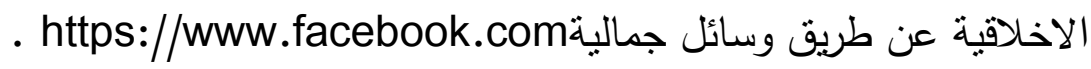


أن بعض الفنون قد زالت خلال الزمن، ومنها ما ظهر في الوقت الحاضر، والفنون تشمل الأنشطة

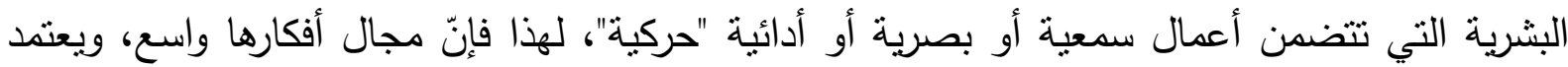
على كمية الإبداع والمفاهيم والمهارات الفنية التي يمتلكها الفنان، كما يعتمد على تقدير المنلقي لهذه الفنون بمعرفته لقوتها العاطفية وجمالها.

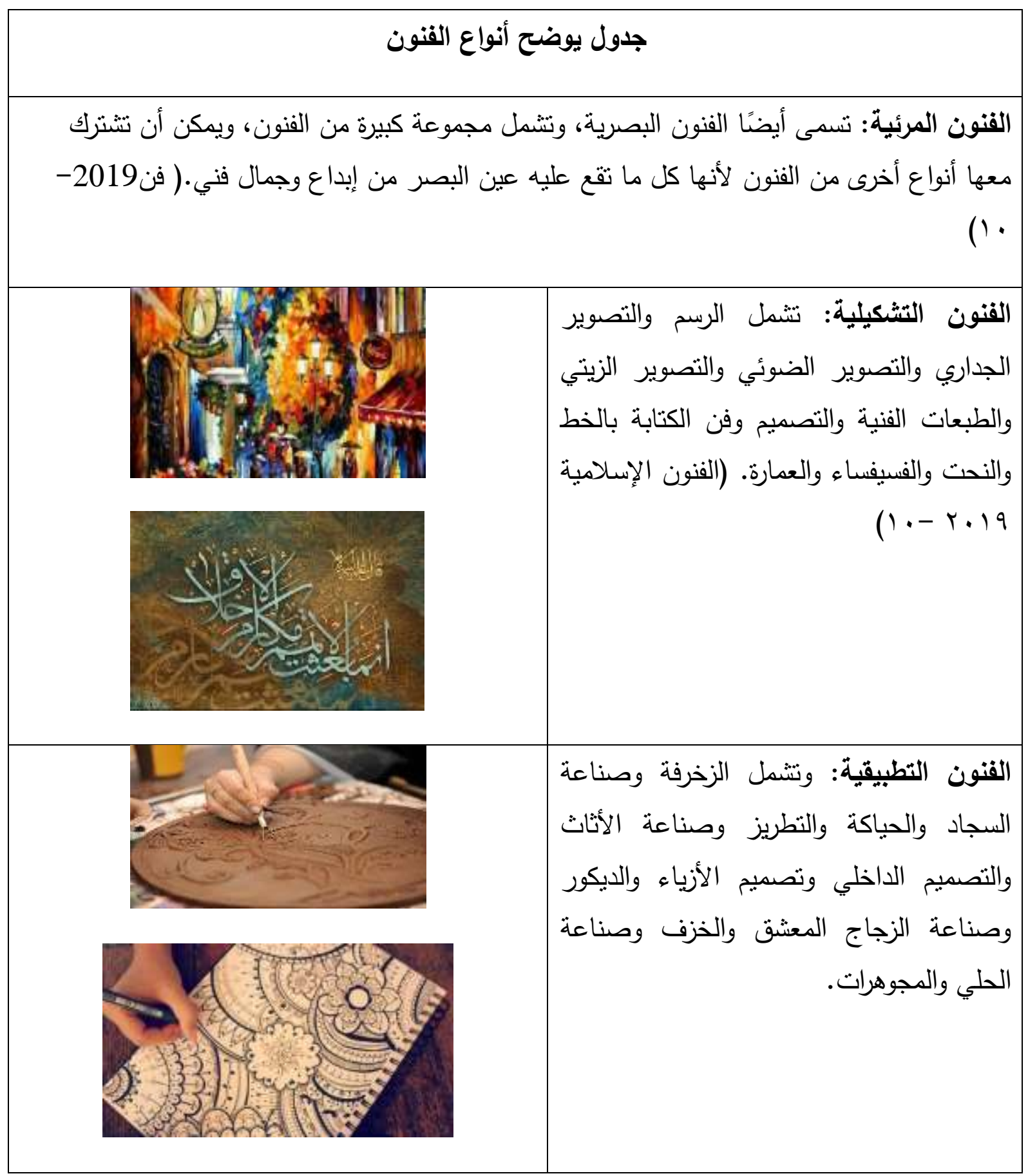




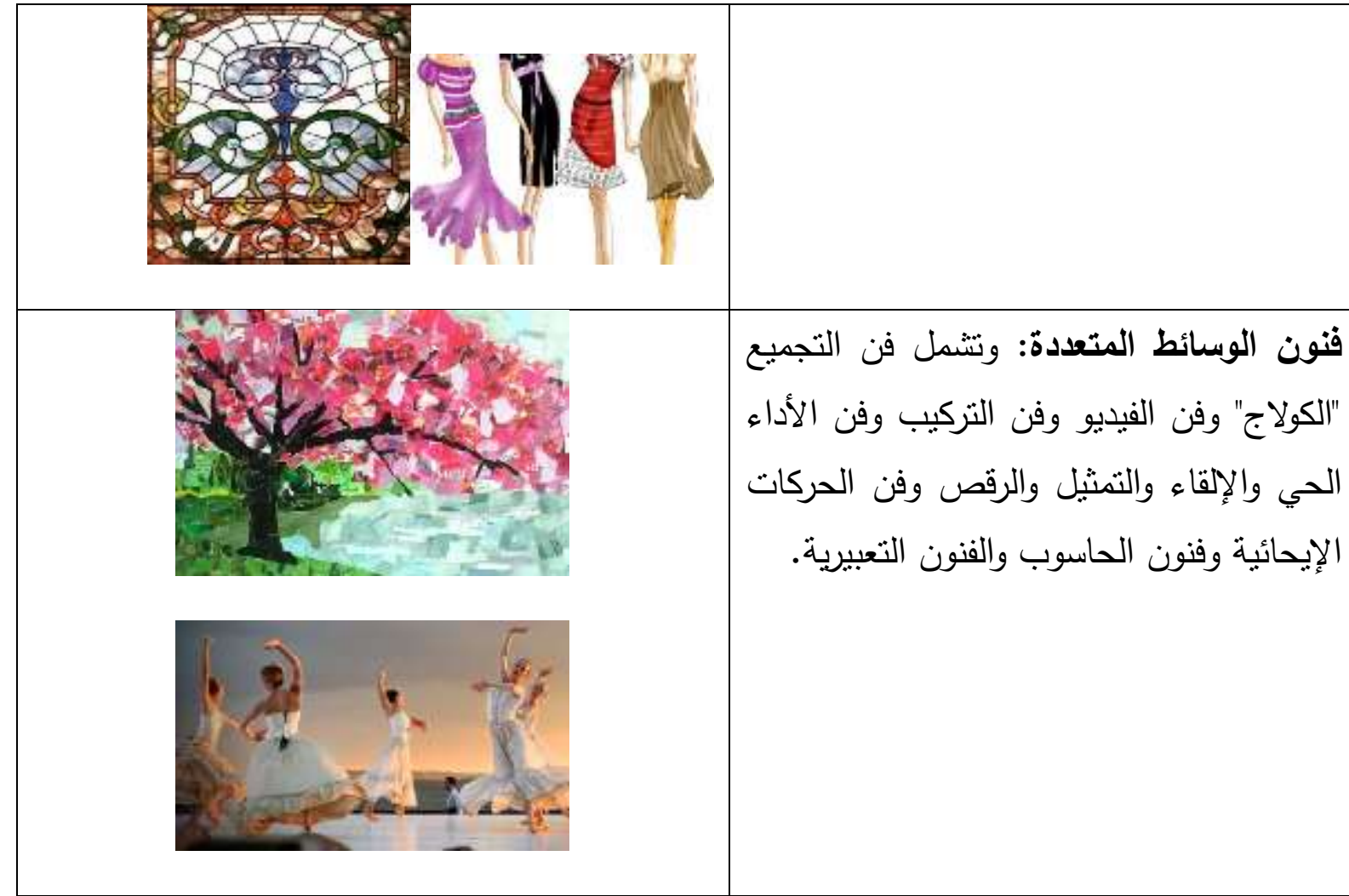

الفنون غير المرئية: تشمل الثعر والمسرح والأدب وفن الطهي والإلقاء والخطابة والأوبرا والغناء والموسيقى.
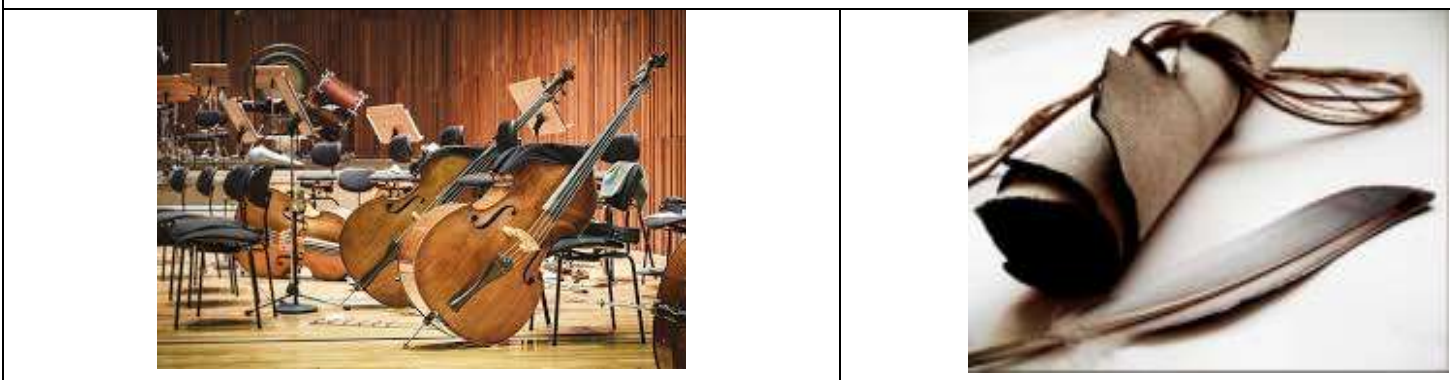

أهمية الفن في المجال الأكاديمي:

يقول الكثير من علماء النفس، إن الثخصية تبدأ في التكون منذ السنوات الأولى من عمر الفرد حيث يبدأ في تعلم الكثير من أنماط السلوك المختلفة التي يكون لنفسه عن طريقها شخصية مميزة خاصة بهاه

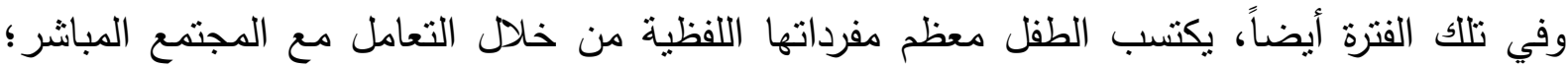
كالأم، والأب، والمعلمين، وزملاء الدراسة والتعلم عموما ونرى أن الطفل بجانب تعلمه السلوك واللغة اللفظبة أيضا، فإنه يتعلم التعبير الفني واستعمال الصور الثكلية للتعبير عما في ذهنه وبطريقته الخاصة.

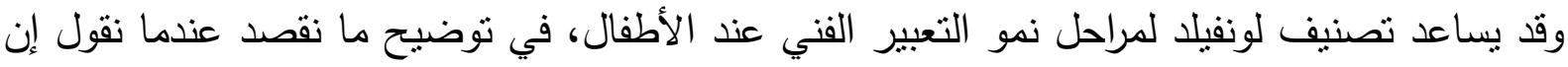


الإنسان بستطيع التعبير عن نفسه من خلال الرسم منذ السنين الأولى في حياته. ( الجمعان، حنان

ودمج الفن في المجال الأكاديمي له دور كبير في تطور العقلية والثقة بالنفس وتطور ملكة الإدرالك

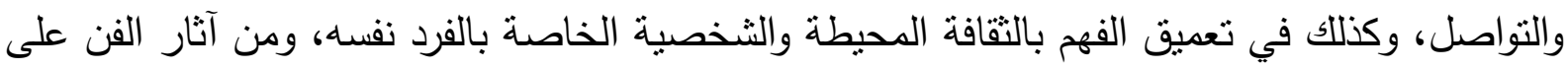

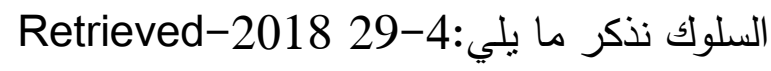
تطور العقلية: من خلال دمج الأنشطة الفنية مع الأكاديمية يطور الفرد مهارات حياتية متعددة كمرونة

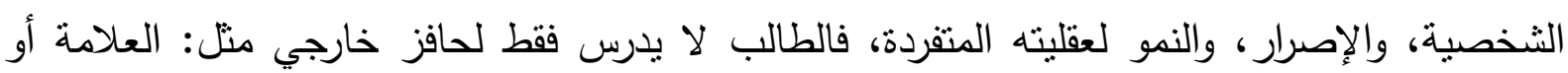

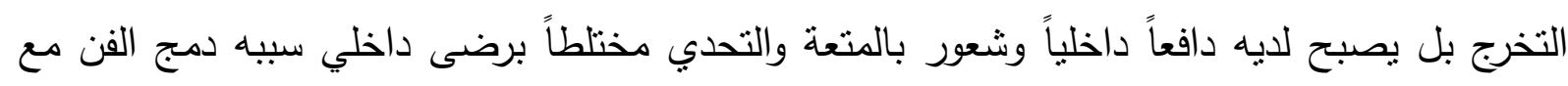

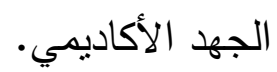

الثقة بالنفس: يمنح الفن فرصة للفرد الخجول لكي يكون عنصراً فاعلاً له صوته المسموع، فحين ينضم

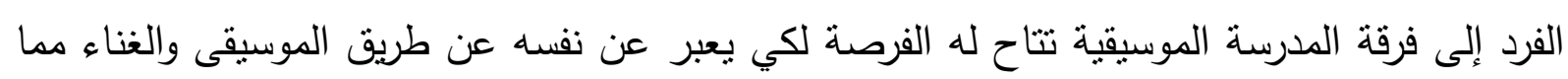
يتيح له تفاعلاً أكبر مع محيط أوسع. تحسين الإدراك: يربط التعليم الفني ربطاً بديعاً بين التعليم الموسيقي وارتفاع مسنويات الإبداع في المواد الدراسية العلمية. زيادة التواصل: إن الانخراط في الفن، أو الإنثاد، أو العمل المسرحي المدرسي يهيئ بيئة مناسبة للتواصل الاجتماعي بين الأفراد.

\section{استخدام الفن كمادة أساسية ضمن المناهين الأدراد الدراسية.}

يعتبر تعليم الفنون لطلبة المدار الابتدائية والمتوسطة والاعدادية من اهم طرق تربية النشأ الجديد وفق النق

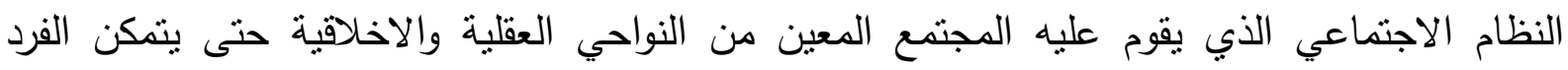

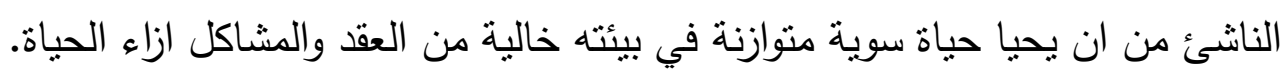

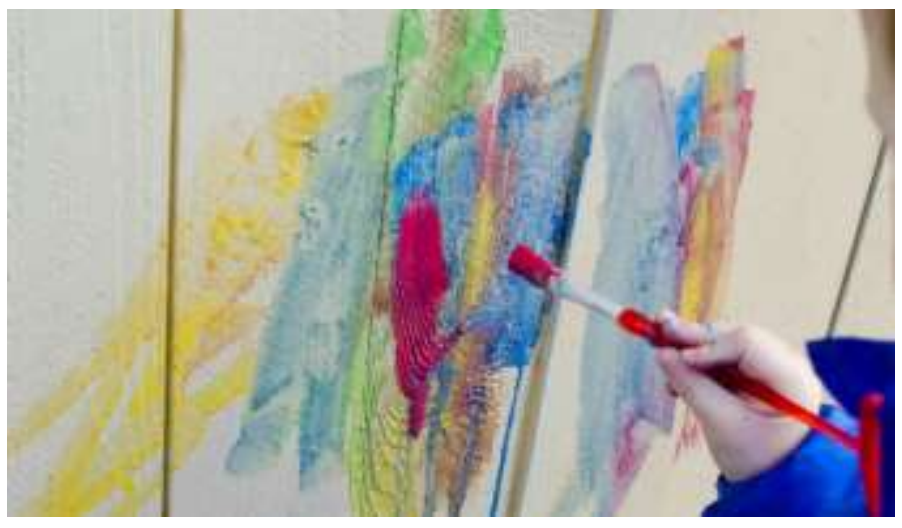

شكل (Y) يعبر عن تعليم الفنون 
وقد اهتم الكثير من التربوبين وعلى امتذاد التاريخ بضرورة إيجاد أفضل الطرق التعليمية من خلال وضع مناهج واساليب توائم مع طبيعة كل مجتمع وكل نمط حياتي تمارسه الامم والشعوب. فكانت طرق التعليم (بالفن) من اولى الطرق التي استخدمت ومن فترات بعيدة لتتشأ الفرد تتشئة سليمة وصحيحة. وكان (الرسم) هو اول ظاهرة اثارت فضول الانسان القديم. وقد جاءت الصورة ثم الكتابة ثم الاثكال الهندية. ولتدريس التربية الفنية دور مهم في بناء شخصية الفرد فهي تساهم مع باقي المواد الدراسية في إعداد الفرد المتكامل الثخصية. ويؤكد الباحثون أهمية الفن التربوبة باعتباره القوى المهذبة لغرائز الإنسان والمتسامية بها إلى المستويات الرفيعة فهو يهذب النفس إلى جانب اكتساب المهارات الفنية ، والتربية الفنية تعد جوهر للتربية الوجدانية التي تغني الثخص روحيا وتكمل اهتمامه الفكرية والعملية ، فتكمل شخصيته الفنية من خلال تتمية المفاهيم السليمة للتذوق والمعايير الصحيحة للاستمتاع بكل حواسه وتعد التربية الفنية جزءا مكملا للعملية التربوية والطفل يجد في الفن خير متتفس لأحاسيسه وانفعالاته ، والمراهق يجد في الفن خير معبر لطموحاته ورغباته الخيالية ، والبالغ يجد في الفن خير معبر لأفكاره وتكوين شخصيته المستقبلية ، ولذا ينبغي أن يمارس التربية الفنية وفق آخر ما توصلت إليه الأبحاث التربوية والنفسية التي تهتم بتعليم الفن حيث تبنى علاقة سوية ومنسجمة مع بعضهما البعض وبهذا نستطيع أن نكون أشخاص منزنين عقليا وسيكولوجيا. فنظم التعليم في البلدان تستهدف في تعليمها تعليم الأفراد المواد العلمية والأدبية وتفضيلها على مواد الفن الأخرى متجاهلة وظيفتها التي هي أكثر وظائف التربية أهمية. لذا فمادة التربية الفنية تعتبر من المواد المهمة في حياة الطالب فهي في الإطار العام لا تقل أهمية عن المواد الأخرى كونها تعمل على بناء شخصية الطالب محور العملية التعليمية.

\section{ويمكن أيضا استخدام الفن من خلال ما يلي:}

ا ـ استخدام اللوحات الفنية بأنثالها الفنية المختلفة من مطبوعة ومصورة ومتحركة إلى جانب أنواعها من

$$
\text { حيث نتاول الموضوعات المختلفة. }
$$

r. التعلم من خلال التقلئبد والمحاكاة من خلال الأثكال الفنية المختلفة . r. التعلم من خلال التجربة التمثيلية لتجربة عواقب السلوك السيء. ع. التعلم من خلال الرسم حيث ينمى الرسم القدرات الحسية ومهارات القراءة والكتابة والصور . ه. استخدام الرسوم التوضيحية التفاعلية لجذب الانتباه وتتمية المهارات واكتساب السلوكيات الصحيحة. التقتيات الحديثة في تعليم القنون: 
يؤكد كل من كووس وسميث- شناك) (1997, Shank )-Smith and Koos في دراستهما أنه يجب التركيز على التقنيات الحديثة في تطبيقات تعليم الفنون كالتعلم عن بعد حيث إن تأثثر التكنولوجيا

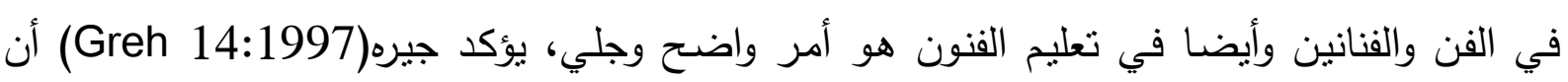

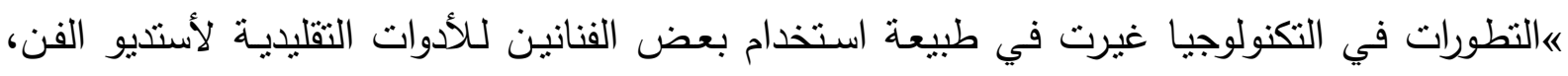

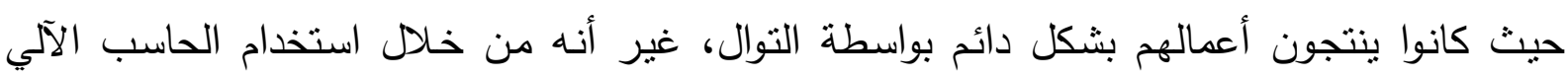

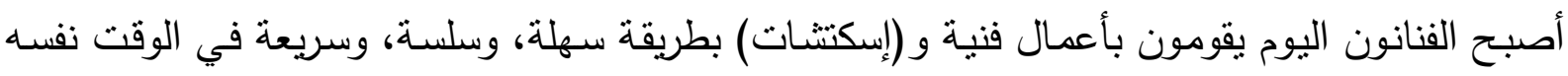

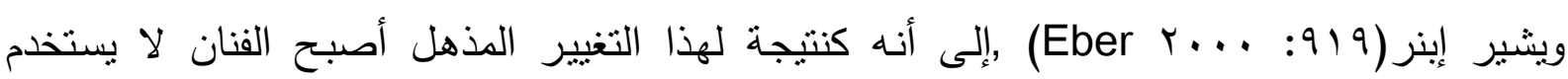

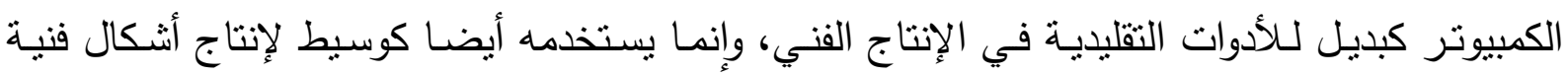

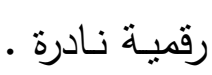
فمن خلال عملية التصوير الرقمي أو الرسم بالحاسب الآلي لأشكال ثنائية وثلاثية الأبعاد إلى الأثكال

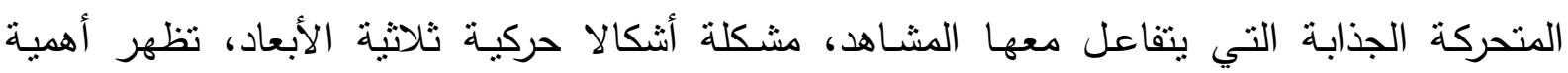

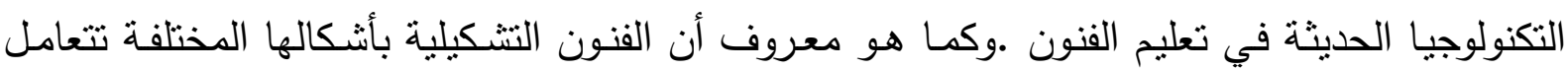
مع معالجة تقليدية لمختلف الخامـات التقليدية مثل الطين، والأوراق، والطباشير وألوان الباستيل

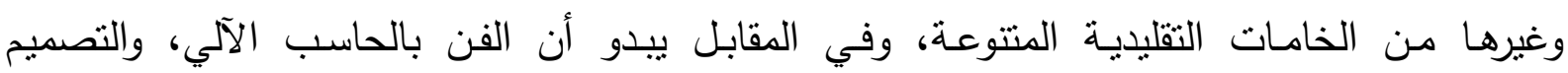

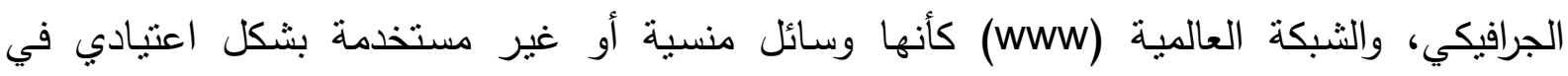

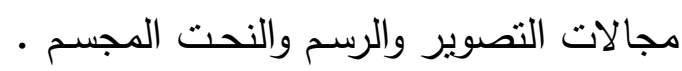
وكنتيجة لذلك فإننا نرى أنه من الواجب إدراك أن التقنيات الحديثة ليست إحلال للتقنيات التقليدية

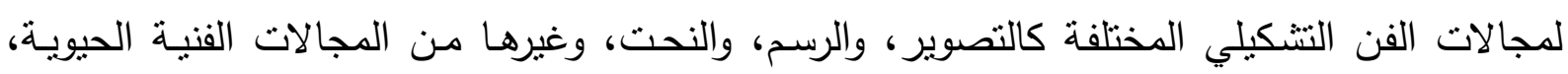

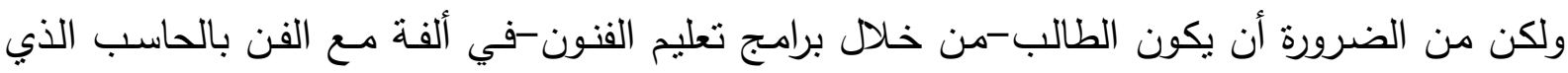

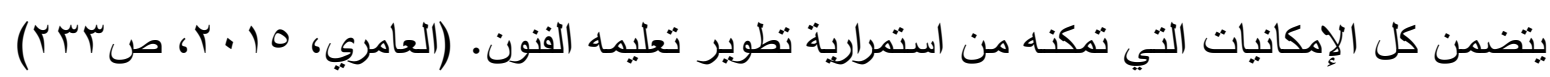

\section{أدوات ووسائل التعلم عن بعد لاراسة القنون:}

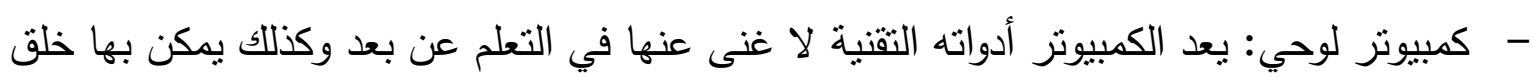
الأعمال الفنية

- الثاشة وتعد من أفضل وسائل الاظهار لعرض الصور والأشكال والمعالجة في الكمبيوتر في عصر التعلم عن بعد. - - إحدى التطبيقات التالية: 


\section{Meet Google \\ Skype \\ Webex \\ Teams. Microsoft \\ Blackboard •}

تلك التطبيقات تقدم الخدمات التعليمية التالية : - التواصل الصوتي والمرئي عبر الإنترنت

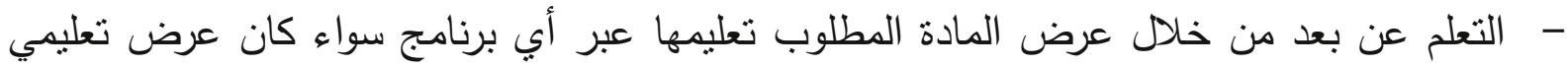

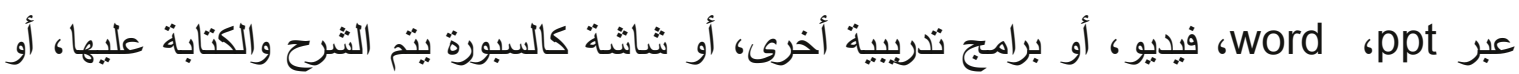

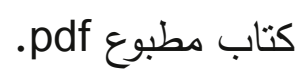
- إمكانية الدخول للجلسة عبر رابط إنترنت، مع إمكانية كتم صوت المشاركين أثناء الحديث، أو السماح لبعضهم بالحديث - إمكانية نسجيل فيديو لما ينت تداوله عبر الجلسة، ثم عرضه عبر أي وسيلة نواصل اجتماعي لحضورها فيما بعد.

- مشاركة شاشة الهاتف أو الحاسب: يمكن من خلال تلك النطبيقات من خلال تلك الواجهة ايضا

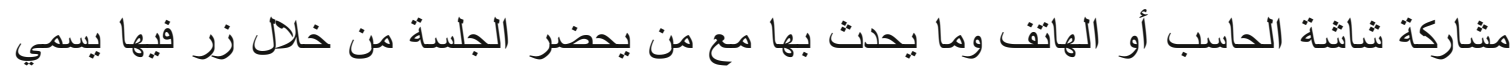
"Screen Share” "والذي ينيح ايضا امكانية شرح برامج التصميم والرسم بأنواعها. التنائج والتوصيات:

أولا: نتائج البحث: تأنى نتائج البحث على ما أكنته الدراسات أن: - الأخلاق تعتد على التدريب المناسب ليكتسب الانسان العادات والأخلاق الحسنة.

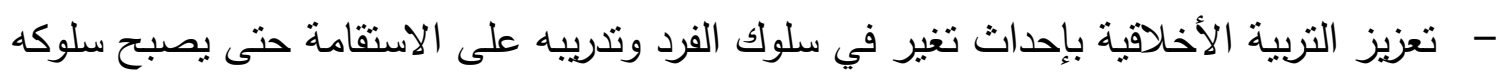
منتظم منذ الصغر من خلال دراسته للفنون المختلفة. - - يوجد مصادر عديدة لإكساب الفرد التربية الأخلاقية. - - نساهم العلوم الحديثة والتقنية المعاصرة في تعميم وتفعيل الدور الاخلاقي للفن.

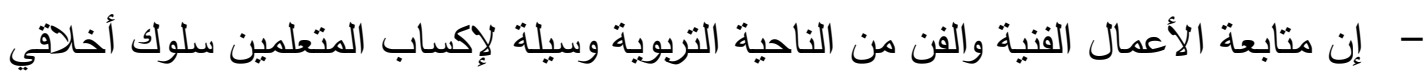
إيجابي. نتائج الاستبيان: - n 
قامت الباحثة بتصميم استبيان للإجابة على التساؤلات الاتية:

ا ـ هل يؤثز الفن على تتمية التربية الأخلاقية؟ (المحور الأول)

r. هل تعزيز التربية الأخلاقية لدى الطلاب يؤثر في جودة التعلم عن بعد؟ (المحور الثاني)

تم اختيار العينة عشوائيا طبقا للجدول التالي:

جدول (1) وصف العينة

\begin{tabular}{|c|c|c|}
\hline النسبة & التصنيف & المتغير \\
\hline 42.4 & ذ ذكور & \multirow[t]{2}{*}{ الجنس } \\
\hline 57.6 & اناث & \\
\hline 5 & أقل من ب سنوات & \multirow[t]{3}{*}{ الخبرة } \\
\hline 19 & من ب - ه سنوات & \\
\hline 66 & أكثر من • سنوات & \\
\hline
\end{tabular}
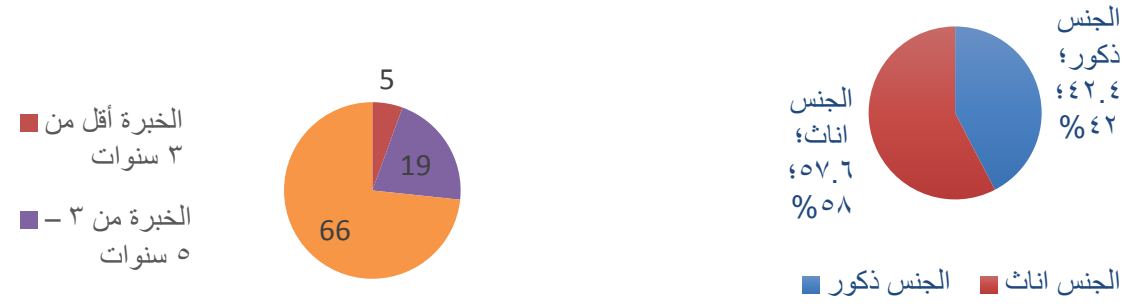

شكل (؛ ) يوضح نسب متغير الخبرة

شكل (ץ) يوضح نسب متغير الجنس

آراء المشاركين في بنود التقيم:

جدول(r) يوضح نسب آراء المشاركين في الاستبيان

\begin{tabular}{|c|c|c|c|c|c|}
\hline معارض & 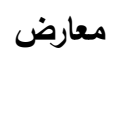 & 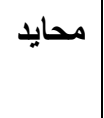 & 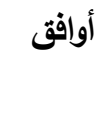 & بثدة اوفق & 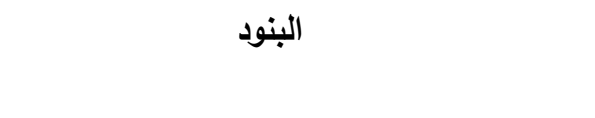 \\
\hline \multicolumn{6}{|r|}{ المحور الأول } \\
\hline 0 & 0 & 0 & 22.7 & 77.3 & يساعد الفن في تدعيم القيم الأخلاقية لدى الفرد \\
\hline 0 & 0 & 0 & 24.2 & 75.8 & تتمي الفنون البصرية القيم الخلقية لدى الطلاب \\
\hline 0 & 0 & 0 & 27.3 & 72.7 & تتمي الفنون المرئية القيم الخلقية لدى الطلاب \\
\hline 0 & 0 & 1.5 & 19.7 & 78.8 & الصغر بـد الفن على تحسين السلوك الأخلاقي منذ \\
\hline \multicolumn{6}{|r|}{ المحور الثاني } \\
\hline 0 & 0 & 1.5 & 22.7 & 75.8 & يجب أن يدرس الفن كمادة أساسية ضمن المناهج \\
\hline 0 & 0 & 9.1 & 18.2 & 72.7 & ترى أنه من المكن تدريس الفن عن بعد \\
\hline
\end{tabular}




\begin{tabular}{|l|c|c|c|c|c|}
\hline 0 & 0 & 3.0 & 24.2 & 72.7 & تنتخدم حصة التربية الفنية لزيادة الوعي الخلقية التربية الاخلاقية تساعد في تحسين جودة التعلم \\
\hline 0 & 0 & 3 & 15.2 & 81.8 & \\
\hline
\end{tabular}

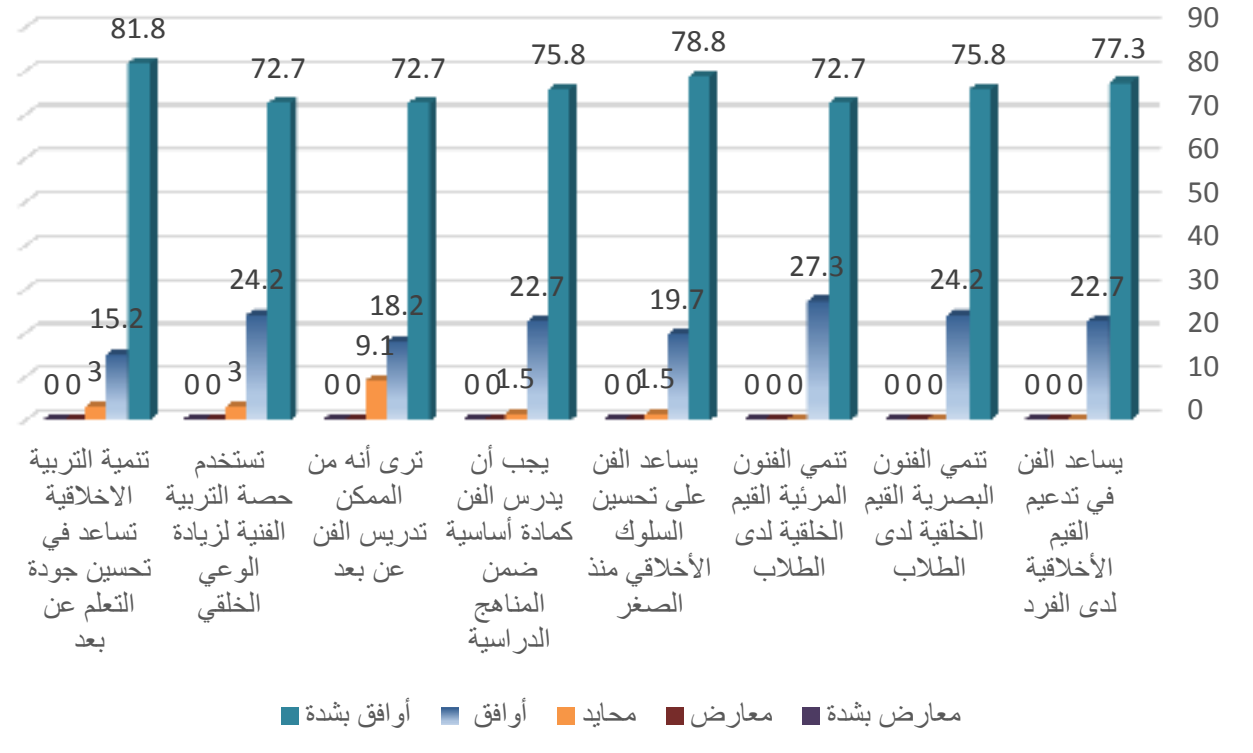

$$
\text { شكل(0) يوضح نسب آراء المشاركين في الاستبيان }
$$

صدق وثبات الاستبيان:

صدق الاستبيان: يقصد به قدرة الاستبيان على قياس ما وضع لقياسه.

جدول(r) حساب معاملات ارتباط بين درجة كل عبارة والدرجة الكلية للعبارات

\begin{tabular}{|c|c|c|}
\hline الد لالة & الارتباط مع & بنود التقييم \\
\hline & & المحور الأول \\
\hline 0.01 & $.837(* *)$ & يساعد الفن في تدعيم القيم الأخلاقية لدى الفرد \\
\hline 0.01 & $.736(* *)$ & تتمي الفنون البصرية القيم الخلقية لدى الطلاب \\
\hline 0.01 & $.807(* *)$ & تتمي الفنون المرئية القيم الخلقية لدى الطلاب \\
\hline 0.01 & $.839(* *)$ & يساعد الفن على تحسين السلوك الأخلاقي منذ الصغر \\
\hline & & المحور الثاني \\
\hline 0.01 & $.785(* *)$ & يجب أن يدرس الفن كمادة أساسية ضمن المناهج الدراسية \\
\hline
\end{tabular}


دور الفنون في تعزيز التربية الأخلاقية لتحسين جودة التعلم عن بعد

\begin{tabular}{|c|c|c|}
\hline 0.01 & $.748(* *)$ & ترى أنه من الممكن تدريس الفن عن بعد \\
\hline 0.01 & $.811(* *)$ & تستخدم حصة التربية الفنية لزيادة الوعي الخلقي \\
\hline 0.01 & $.757(* *)$ & تتمية التربية الاخلاقية تساعد فى تحسين جودة التعلم عن بعد \\
\hline
\end{tabular}

جدول(ع) حساب معاملات ارتباط بين درجة كل محور والدرجة الكلية للعبارات

\begin{tabular}{|c|c|c|}
\hline 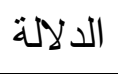 & الازتباط مع المجموعة & المحاور \\
\hline 0.01 & $.752(* *)$ & المحور الأول \\
\hline 0.01 & $.752(* *)$ & المحور الثاني \\
\hline
\end{tabular}

يتضح من الجدول r، ؛ أن معامالات الارتباط كلها دالة عند مستوى (0.01) لاقترابها من الواحد الصحيح مما يدل عل صدق وتجانس عبارات الاستبيان.

يقصد بالثبات: دقة الاختبار في القياس والماحظة وعدم تتاقضه مع نفسه واتساقه واطراده فيما يزودنا به من معلومات عن سلوك المفحوص وهو النسبة بين تباين الدرجة على المقياس التي تشير الى الأداء الفعلي للمفحوص وتم حساب الثبات عن طريق: ا ـ Cronbach's Alpha معامل الفا كرونباخ

Y Guttman Split-Half Coefficient طريقة التجزئة النصفية جدول(0) يوضح قيم معامل الثبات لعبارات الاستبيان

\begin{tabular}{|c|c|c|}
\hline \multicolumn{2}{|c|}{ Reliability Statistics } \\
\hline N of Items & Cronbach's Alpha & Guttman Split-Half Coefficient \\
\hline 8 & .908 & 0.854 \\
\hline
\end{tabular}

يتضح من الجدول السابق أن جميع قيم معاملات الثبات معامل الفا ، التجزئة النصفية دالة عند مستوى 0.01 مما يدل على ثبات الاستبيان.

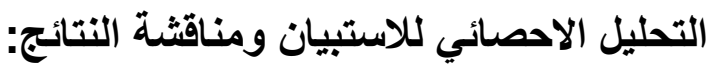

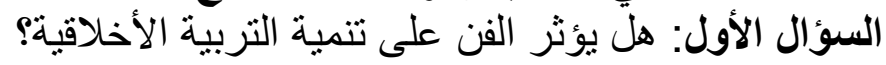

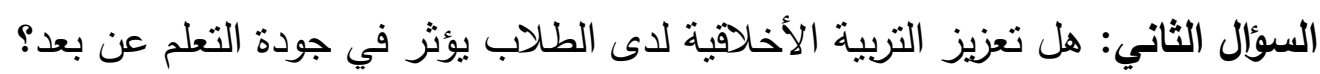


للإجابة على هذا تم استخراج البيانات الوصفية من متوسطات حسابية وانحرافات معيارية وأوزان نسبية ودرجات التقدير لكل محور وجاءت النتائج كالتالي:

جدول ( T) ويوضح المتوسط و الانحراف المعياري و الترتيب البنود من خلال استجابات المشاركين

\begin{tabular}{|c|c|c|c|c|}
\hline الثسبي & $\begin{array}{c}\text { Std. } \\
\text { Deviation } \\
\text { الألحر افياري }\end{array}$ & $\begin{array}{l}\text { Mean } \\
\text { المتوسابي }\end{array}$ & المحاور & م \\
\hline & & & المحــــــور الأول & \\
\hline 77.3 & .42228 & 2.7727 & يساعد الفن في تدعيم القيم الأخلاقية لدى الفرد & .1 \\
\hline 75.8 & .43183 & 2.7576 & تتمي الفنون البصرية القيم الخلقية لدى الطلاب & .4 \\
\hline 72.7 & .44877 & 2.7273 & تتمي الفنون المرئية القيم الخلقية لدى الطلاب & r \\
\hline 78.8 & .45726 & 2.7727 & يساعد الفن على تحسين السلوك الأخلاقي منذ الصغر &.$\varepsilon$ \\
\hline 76.15 & 0.4400 & 2.7575 & \multicolumn{2}{|c|}{ مجموع المتوسطات للمحور الأول } \\
\hline \multicolumn{5}{|c|}{ المحــور الثاني } \\
\hline 75.8 & .47428 & 2.7424 & يجب أن يدرس الفن كمادة أساسية ضمن المناهج الدراسية & .0 \\
\hline 72.7 & 64775 & 2.6364 & ترى أنه من الممكن تدريس الفن عن بعد & .7 \\
\hline 72.7 & .52535 & 2.6970 & تستخدم حصة التربية الفنية لزيادة الوعي الخلقي &.$\vee$ \\
\hline 81.8 & .48087 & 2.7879 & تتمية التربية الاخلاقية تساعد في تحسين جودة التعلم عن بعد &.$\wedge$ \\
\hline 75.75 & 0.5320 & 2.7159 & مجموع المتوسطات للمحور الثاني & \\
\hline
\end{tabular}

ويتضح من الجدول (T) ان استجابة العينة عن البنود تشير الى تقديرات مرتفعة في المحورين فقد بلغ المتوسط الحسابي الكلي للحور الأول (2.75 ) وانحراف معياري (440.). وبلغ المتوسط الحسابي الكلي للمحور الثاني (2.71 ) وانحراف معياري(0.532 ) مما يدل على انسجام أراء العينة في الاستبيان.

كما أن المتوسطات الحسابية لبنود الاستبيان تراوحت ما بين (2.78-2.63) بتقديرات مرتفعة لكل البنود وجاء بالمرتبة الأولى البند (^) والذى ينص على أن (تتمية التربية الأخلاقية تساعد في تحسين جودة التعليم عن بعد ) وجاء بمتوسط حسابي (2.736) وانحراف معياري(0.480) وجاء بالمرتبة الثانية البندين ( (، ع) اللذان نصا على (بساعد الفن في تدعيم القيم الأخلاقية لدى الفرد و هل يساعد الفن على 
تحسين السلوك الأخلاقي منذ الصغر) وجاءا بمنوسط حسابي (2.77) وانحراف معياري ( 42228. و 45726.) وجاء بالمرتبة الثالثة البندين رقم (Y) والذى نص على (تتمي الفنون البصرية القيم الخلقية لدى الطلاب ) وجاءا بمتوسط حسابي (2.7576 ) وانحراف معياري (64775.) وجاء بالمرنبة الرابعة البند رقم (0) والذى نصا على ( يجب أن يدرس الفن كمادة أساسية ضمن المناهج الدراسية )وجاء بمتوسط حسابي (2.7424) وانحراف معياري( 43183.) وجاء بالمرنبة الخامسة البند(ب) والذى نص على (تمي الفنون المرئية القيم الخلقية لدى الطلاب) وجاء بمتوسط حساب(2.7273) وانحراف معياري (44877.) وجاءا بالمرتبة الأخيرة البندين (T، V) والذي نصا على (هل ترى أنه من الممكن تدريس الفن عن بعد و تستخدم حصة التربية الفنية لزيادة الوعي الخلقي) وجاءا بمتوسط حسابي(2.6 ) ويتضح مما سبق بوجود اتفاق بين آراء المشاركين في استجابات الاسنتيان.

الفروق بين سنوات الخبرة:

جدول (V) نتائج تحليل التباين الأحادي (ANOVA) ومستوى الدلالة لتصور المشاركين في الاستبيان

\begin{tabular}{|c|c|c|c|c|c|c|}
\hline Sig. & $\mathbf{F}$ & $\begin{array}{c}\text { Mean } \\
\text { Square }\end{array}$ & df & $\begin{array}{l}\text { Sum of } \\
\text { Squares }\end{array}$ & مصدر التباين & المحاور \\
\hline \multirow[t]{3}{*}{.342} & 1.091 & 2.544 & 2 & 5.087 & Between Groups & \multirow[t]{3}{*}{ المحور الأول } \\
\hline & & 2.331 & 63 & 146.852 & Within Groups & \\
\hline & & & 65 & 151.939 & Total & \\
\hline \multirow[t]{3}{*}{.525} & .650 & 2.001 & 2 & 4.001 & Between Groups & \multirow[t]{3}{*}{ المحور الثاني } \\
\hline & & 3.076 & 63 & 193.771 & Within Groups & \\
\hline & & & 65 & 197.773 & Total & \\
\hline
\end{tabular}

ومن التحليل السابق اتضح أنه لا توجد فروق ذات دلاله إحصائية بين متوسطات الدرجات تبعا لمتغير سنوات الخبرة بالمحور الأول والثاني.

ثانيا التوصيات:

- توصى الباحثة بتدريس الفنون للطلبة كمادة أساسية في جميع التخصصات. - التأكيد على أهمية الفن في تشكيل سلوك الفرد وتعزيز التربية الاخلاقية. - التأكيد على أهمية البحث في المواضيع الفنية والثقافة الفنية بشكل عام. - الفن خالد خلود الحضارة وقائم ما قامت الحضارة. ومع ذلك فهو بحاجة إلى حماية ورعاية. 


\section{المراجع}

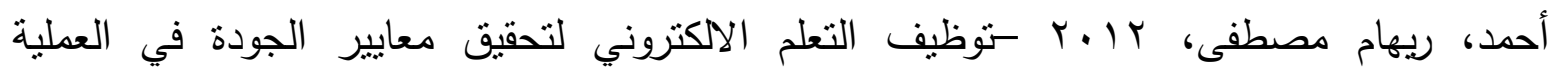
التعليمية-المجلة العربية لضمان جودة التعليم المصري-العدد(9).

الجمعان، حنان 9 ( ـ - التفاعل والتذاخل وإثكالية العلاقة بين الفن والعلم منذ فجر الحضارة وحتى

عصر التكنولوجيا - مجلة الفنون والأدب وعلوم الانسانيات والاجتماع -العدد ؟r.

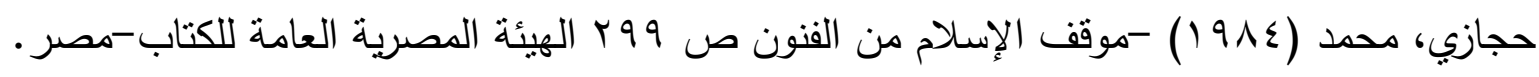
الحسين، إبراهيم r I ـ ب - القيم في الفن والجمال - مجلة عالم التربية. الحيضي، صلاح - التربية الأخلاقية وأثزها في بناء مستقبل الثباب-مؤتمر الثباب وبناء المستقبلشبكة الألوكة.

الصباغ، روضان r...r جماليات الفن الإطار الأخلاقي والاجتماعي - دار الوفاء لدنيا الطباعة

$$
\text { والنشر - مصر. }
$$

العامري، محمد حمود، 10 • ب - الاتجاهات المعاصرة في التربية الفنية - مجلة الأدب والعلوم الاجتماعية - جامعة السلطان قابوس.

$$
\text { العجمي -زينب -جامعة السلطان قابوس. }
$$

العراقي، سهام محمود (ع 9 (م). في التربية الأخلاقية مدخل لتطوير التربية الدينية، مكتبة المعارف

$$
\text { الحديثة - حمادة زغلول. }
$$

العقاد، التفكير فريضة إسلامية ص V - -طبعة دار الهلال. الياسري، صبا | 1 • ب-الفن ودوره الاجتماعي والتربوي وإمكانية التفعيل في المجتمعات العربية. سعد، عبد المنعم فهمي (• ( • rم). إثكالات تربوية، الدار الثقافية للنشر ، القاهرة، مصر • شيخي، عزيزة \9919 - الفن والأخلاق - الجمعية العربية السعودية للثقافة والفنون. طراد، محمد السيد (11 • rم). سبيل الآباء في تربية الأبناء، عالم الكتب، القاهرة، مصر. ليف، جميلة شحادة (1 . . r.م). أخلاقيات القيادة، دار اقرأ للنشر والتوزيع، حولي، الكويت. ناصر ، إبراهيم (ج . . ץم). التربية الأخلاقية، دار وائل للنشر، عمان، الأردن. 
دور الفنون في تعزيز التربية الأخلاقية لتحسين جودة التعلم عن بعد

Eber, D., 2000, Computer graphic curricula in the visual arts. Computer and

Graphic, 24, pp919- 923. [Available on line from]

www.elsevier.com/ locate/cag.

Greh, D., 1997, New Technologies in the Art Education. In: Gregory, D.

(ed), New Technologies in Art Education: Implications for Theory,

Research, and Practice, Reston, VA, National Art Education

Association, pp.13-21.

K. Barker (2004). Canadian Recommended E-Learning Guidelines, FutuED Inc., Canada.

Koos, M. and Smith-Shank, D., 1997, The World Wide Web: Alice Meets

Cyberspace, In: Gregory, D. (ed), New Technologies in Art

Education: Implications for Theory, Research, and Practice,

Reston, VA: National Art Education Association, pp.33-40.

"How the ARTS Benefit Student Achievement", pages(12-16),

"الفنون الإسلامية"، www.alukah.net"

"تاريخ الفن"، www.wikiwand.com

أ ب "فن"، www.wikiwand.com.

الإسلام والفن الملتزم"، www.saaid.net.

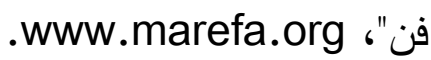

https://www.for9a.com/specialities

https://www.facebook.com/arch4human/posts/628901973821805

https://anwaar.squ.edu.om/blogs/2020/09/27. 